\section{Congenital malaria in one non-identical twin}

Only seven cases of congenital malaria have been reported in Britain. ' + The case described here is believed to be the first to be reported in a binovular twin.

\section{Case history}

Shortly after her arrival in England from India in 1974, the mother, a 23-year-old primigravida, was found to have pulmonary tuberculosis, which was treated with streptomycin, rifampicin, and isoniazid. She became pregnant in September 1975, and her treatment was changed to paraaminosalicylic acid and isoniazid. Twin pregnancy was diagnosed radiologically in April 1976. The mother was admitted to hospital later that month in premature labour and delivered live male twins on 26 April 1976. The placenta and membranes were normal and consistent with the twins being binovular

Twin I was delivered as a vertex presentation using Wrigley's forceps. Apart from transient anaemia his progress was uneventful. Repeated blood films showed no evidence of malaria.

Twin II was found to have a transverse lie. External version was unsuccessful. The membranes ruptured spontaneously and a hand prolapsed. He was subsequently delivered by internal version and breech extraction under general anaesthesia. He weighed $2.3 \mathrm{~kg}$ and was estimated to be of 35 weeks' gestation. A mild degree of Erb's palsy on the left soon resolved. He became jaundiced in the neonatal period, the serum bilirubin level reaching $229 \mu \mathrm{mol} / 1(13.4 \mathrm{mg} / 100 \mathrm{ml})$ on the fifth day, then rapidly subsiding. He continued to thrive until 42 days, when he became febrile with a rectal temperature of $38.2 \mathrm{C}$. There was no obvious cause for this and he was feeding well, though he was noticed to be pale. The pulse rate was $160 / \mathrm{min}$ and there was a soft systolic ejection murmur at the apex. The liver and spleen were enlarged.

A blood count was performed, the haemoglobin level being $6 \mathrm{~g} / \mathrm{dl}$; the total white cell count $5 \cdot 10^{9} / 1$, with $8 \%$ neutrophils, $86^{\circ}$, lymphocytes, and $6 \%$ monocytes. Plasmodium vivax was seen in the film. Blood films were subsequently examined at the Malaria Reference Laboratory at the London School of Hygiene and Tropical Medicine, confirming the diagnosis. The results of a chest $x$-ray film, lumbar puncture, and cultures of blood and urine were all normal. Treatment was begun with chloroquine base, $75 \mathrm{mg}$ orally, repeated after six hours, and then $37.5 \mathrm{mg}$ orally daily for four days. Response to treatment was excellent, the liver and spleen rapidly becoming impalpable. No parasites were seen in the blood films after the fourth day and subsequent follow-up has shown continued improvement in the anaemia and no recurrence of the malaria.

Serological studies on blood from the mother and both twins gave results consistent with the findings described. The results are summarised in the table. The titres for the mother and twin II are consistent with recent $P$ vivax malaria, the fall in titre for twin II suggesting successful treatment. The antibodies in twin I were thought to be of transplacental origin and might be expected to persist for several months. Blood films from the mother were not examined.

Ma!arial antibody titres in the mother and twins

\begin{tabular}{|c|c|c|c|}
\hline & & \multicolumn{2}{|c|}{ Antibody titre to: } \\
\hline & & $P$ falciparum & $P$ fieldi (for $P$ vivax) \\
\hline $\begin{array}{l}\text { Mother } \\
\text { Twin I } \\
\text { Twin II }\end{array}$ & $\begin{array}{l}\text { (21 June) } \\
\text { (21 June) } \\
\text { (3 August) } \\
\text { (21 June) } \\
\text { (3 August) }\end{array}$ & $\begin{array}{r}64 \\
16 \\
16 \\
16 \\
0\end{array}$ & $\begin{array}{c}>64 \\
64 \\
16-64 \\
256 \\
16-64\end{array}$ \\
\hline
\end{tabular}

\section{Comment}

In discussions on the mode of transmission of the malarial parasite to the fetus some authors have mentioned the possibility of transmission in the absence of placental damage. Others have suggested that placental trauma may be important. Wilcocks and Manson-Bahr state that congenital infection may occur without obvious placental damage, but suggest that microscopic areas of damage may be present. In the case reported it may be relevant that only the second twin appears to have been infected and that he was delivered after manipulations which could possibly have damaged the placenta, while the unaffected first twin was delivered without difficulty.

I wish to thank Dr B S Davies for her help in the preparation of this report; Dr N D Gower, consultant pathologist, who examined the initial blood films; and Dr C C Draper, who performed the serological studies for the Malaria Reference Service at the London School of Hygiene and Tropical Medicine.

1 Jenkins, H G, British Medical fournal, 1957, 1, 88.

? Dimson, S B, British Medical fournal, 1954, 2, 1083.

'Gammie, R P, Lancet, 1944, 2, 375.

${ }^{4}$ Dodge, J S, Transactions of the Royal Society of Tropical Medicine and Hygiene, 1971, 65, 689.

5 Wilcocks, G, and Manson-Bahr, P E C, Manson's Tropical Diseases, p 41. London, Baillière Tindall, 1972.

(Accepted 27 April 1977)

Paediatric Department, Hallam Hospital, West Bromwich

A J BRADBURY, $\mathrm{MB}, \mathrm{DCH}$, senior house officer (present address: Birmingham Maternity Hospital, Queen Elizabeth Medical Centre, Birmingham B15 2TH

\section{Erythema elevatum diutinum and IgA myeloma: an interesting association}

Erythema elevatum diutinum (EED) is a rare skin disease, thought to be an allergic cutaneous vasculitis of the necrotising leucocytoclastic type. ${ }^{1}$ It consists of symmetrical red or purple nodules or plaques, mainly on the extensor surfaces of joints, which heal after many years leaving hyperpigmentation but no scarring. We report a case of IgA myeloma in a patient who was previously known to have both EED and IgA paraproteinaemia.

\section{Case report}

A 53-year-old woman was admitted to hospital complaining of severe weakness and pain in the chest, right shoulder, and right hip. About nine years previously she had developed a symmetric, non-pruritic erythema consisting of papules, nodules, and reddish plaques affecting mainly the extensor surfaces of the hands and legs. After various unsuccessful treatments over a period of four years she was admitted to the dermatology department of another hospital. Multiple skin biopsies showed changes characteristic of EED-endothelial swelling of the capillaries and perivascular hyaline degeneration, intense inflammatory infiltration consisting mainly of neutrophils, some of which showed apparent leucocytoclasis; extravasation of red cells; and intensive fibroblastic and histiocytic proliferation with fibrosis of the corium and subcutis. Serum immunoelectrophoresis showed an $\operatorname{IgA}$ paraproteinaemia. The bone marrow smears were compatible with an autoimmune disease but showed no evidence of myeloma. She was treated initially but unsuccessfully with azathioprine and then with sulphapyridine with satisfactory results. This was continued for some months.

On admission to our department the patient was pale. She had areas of skin atrophy and pigmentation on her buttocks, thighs, extensor surfaces of arms, and especially on the posterior and interior surfaces of her legs. The right clavicle was fractured and some ribs were painful on pressure. Investigations showed haemoglobin $9.4 \mathrm{~g} / \mathrm{dl}$; WBC $7 \times 10^{9} / 1\left(7000 / \mathrm{mm}^{3}\right)$, differential count normal; ESR $63 \mathrm{~mm}$ in first hour; blood urea nitrogen $22.1 \mathrm{mmol} / 1(62 \mathrm{mg} / 100 \mathrm{ml})$; serum albumin $43 \mathrm{~g} / 1$; serum globulins $29 \mathrm{~g} / \mathrm{l}$; serum calcium $4.0 \mathrm{mmol} / 1(16 \mathrm{mg} / 100 \mathrm{ml})$. There was a trace of proteinuria. Serum protein electrophoresis showed albumin $57.9 \%, \alpha_{1}$ globulin $4.6 \%, \alpha_{2}$-globulin $7.4 \%, \beta$-globulin $4.6 \%, \gamma$-globulin $7.9 \%$. An M-component between $\beta$ - and $\gamma$-globulins measured $17 \cdot 6 \%$. Immunoelectrophoresis with mono- and polyvalent immune sera showed IgA paraproteinaemia with a decrease of IgM and IgG. No Bence Jones proteinuria was found. Result of Sia water dilution test was negative. Bone marrow smears showed extensive infiltration by abnormal plasma cells. Radiographs showed osteolytic lesions in ribs, left humerus and clavicle, skull, and pelvis and a fractured right clavicle. The patient clearly had an IgA myeloma but no evidence of active skin disease was found. She was given melphalan and corticosteroids and radiotherapy for the painful bone deposits. After 10 weeks she was discharged feeling much better. A year later she relapsed and was readmitted.

\section{Comment}

Paraproteinaemia is associated with various autoimmune skin diseases (especially pyoderma gangrenosum) ${ }^{23}$ and hypersensitivity reactions. ${ }^{2}$ 